\title{
ỨNG DỤNG CÔNG NGHÊ VIỄN THÁM VÀ GIS NGHIÊN CƯU VẬT LIỆU CHÁY TRONG CÁC KIỂU RỪNG PHỤC VỤ CÔNG TÁC PHÒNG CHỐNG CHÁY RÙNG TẠI TİNH BĂC GIANG
}

\author{
PHAM MINH HẢI ${ }^{(1)}$, VŨ NGỌC PHAN ${ }^{(2)}$ \\ ${ }^{(1)}$ Viện Khoa học Đo đạc và Bản đồ, ${ }^{(2)}$ Trường Đại học Tài nguyên và Môi trường Hà Nội
}

\section{Tóm tắt:}

Cháy rừng đã gây nên những hậu quả tiêu cực lớn đến môi trường sống, nguồn tài nguyên thiên nhiên và con người. Biến đổi khí hậu với những đợt nóng hạn kéo dài bất thường đã làm cho cháy rừng trở thành thảm hoạ ngày càng nghiêm trọng. Các công trình nghiên cứu về công tác phòng chống cháy rừng tại Việt Nam cho thấy công tác dụ̂ báo phòng chống cháy rừng hiện nay còn tồn tại một số hạn chế, chủ yếu sử dụng dữ liệu khí tượng mặt đất, việc sử dụng ảnh viễn thám trong dụ báo cấp cháy rừng chỉ đến cấp tỉnh, chưa có nghiên cứu nào đi sâu vào nghiên cứu ảnh hưởng của vật liệu cháy cũng như hệ số cháy của chúng đến các hiện tượng cháy rừng. Việc phát triển một giải pháp mới ứng dụng viễn thám nghiên cứu về vật liệu cháy phục vụ công tác dụ̣ báo nguy cơ cháy rừng đóng vai trò cấp thiết cao, trợ giúp hiệu quả cho công tác phòng chống cháy rừng của cơ quan chuyên trách tại địa phương. Địa điểm thử nghiệm của nghiên cứu là huyện Sơn Động, tỉnh Bắc Giang với hai loại hình rừng là rừng trồng và rừng tự nhiên.

\section{Giới thiệu chung}

Cháy rừng là hiện tượng phổ biến, xảy ra ở hầu hết các quốc gia có rừng trên thế giới, trong đó có Việt Nam. Cháy rừng đã gây nên những hậu quả tiêu cực lớn đến môi trường sống, nguồn tài nguyên thiên nhiên và con người, phạm vi ảnh hưởng của cháy rừng không chỉ dừng ở mỗi một quốc gia nào mà cả khu vực và toàn cầu. Trong vài thập kỷ gần đây, biến đổi khí hậu với những đợt nóng hạn kéo dài bất thường đã làm cho cháy rừng trở thành thảm hoạ ngày càng nghiêm trọng. Các công trình nghiên cứu về công tác phòng chống cháy rừng tại Việt Nam có thể đưa ra một số kết luận sau:

- Công tác dự báo phòng chống cháy rừng hiện nay chủ yếu sử dụng dữ liệu khí tượng mặt đất
- Việc sử dụng ảnh viễn thám trong dự báo cấp cháy rừng chỉ đến cấp tỉnh

- Chưa có nghiên cứu nào đi sâu vào nghiên cứu ảnh hưởng của vật liệu cháy cũng như hệ số cháy của chúng đến các hiện tượng cháy rừng. Do vậy, việc phát triển một giải pháp mới ứng dụng viễn thám nghiên cứu về vật liệu cháy phục vụ công tác dự báo nguy cơ cháy rừng đóng vai trò cấp thiết cao, trợ giúp hiệu quả cho công tác phòng chống cháy rừng của cơ quan chuyên trách tại địa phương.

Theo Bế Minh Châu (2001), cháy rừng là sự xuất hiện và lan truyền của những đám cháy trong rừng mà không nằm trong sự kiểm soát của con người, gây nên những tổn thất về nhiều mặt tài nguyên, của cải và môi trường. 
Cháy rừng chỉ có thể xảy ra khi có sự kết hợp đồng thời của ba nhân tố cơ bản đó là oxy, vật liệu cháy và nhiệt lượng (nguồn lửa). Trong đó, vật liệu cháy là chất bị cháy, có sẵn trong rừng. Vật liệu cháy là tất cả những chất có khả năng bén lửa và bốc cháy trong điều kiện có đủ nguồn nhiệt và oxy. Mỗi yếu tố trên được xem là một cạnh của tam giác, ghép chúng lại với nhau tạo thành " tam giác lửa" như hình 1 (xem hình 1). Nếu thiếu một trong ba nhân tố đó, sự cháy sẽ không xảy ra.

Với cách tiếp cận nghiên cứu về vật liệu cháy, yếu tố quan trọng quyết định khả năng bắt lửa cũng như tốc độ lan tràn và quy mô của đám cháy, nhóm nghiên cứu tiến hành nghiên cứu ứng dụng công nghệ viễn thám và GIS nghiên cứu vật liệu cháy trong các kiểu rừng phục vụ công tác phòng chống cháy rừng với địa điểm thử nghiệm tại huyện Sơn Động, tỉnh Bắc Giang. Đối tượng nghiên cứu là rừng trồng và rừng tự nhiên.

\section{Cơ sở khoa học}

\subsection{Phân cấp nguy cơ cháy rừng}

Hiện nay, ngành Kiểm lâm nước ta sử dụng 5 cấp nguy cơ cháy gồm: nguy cơ cháy thấp (Cấp I), nguy cơ cháy trung bình (Cấp II), nguy cơ cháy cao (Cấp III), nguy hiểm (Cấp IV) và cực kỳ nguy hiểm (Cấp V) theo Quyết định số 127/2000/QĐ-BNN-KL ngày 11/12/2000 của Bộ trưởng Bộ Nông nghiệp và Phát triển nông thôn phục vụ công tác dự báo cháy rừng (Bảng 1 ). Tuy nhiên, trên thực tế rất khó để phân biệt và phân định rõ ràng cấp nguy hiểm và cấp cực kỳ nguy hiểm. Vì vậy, nghiên cứu này đề nghị gộp Cấp IV (nguy hiểm) và Cấp V (cực kỳ nguy hiểm) thành một cấp và đề xuất 04 cấp để phân loại thảm thực vật rừng dễ cháy và thành lập bản đồ phân vùng nguy cơ cháy rừng cho huyện Sơn Động tỉnh Bắc Giang như mô tả trong bảng (xem bảng 1).

\subsection{Lựa chọn các chỉ tiêu cho phân} loại thảm thực vật rừng theo nguy cơ cháy

a) Cơ sở lựa chọn các chỉ tiêu:

Trên cơ sở kế thừa các nghiên cứu trước, ý kiến của chuyên gia và phân tích các yếu tố ảnh hưởng đến quá trình cháy rừng ở huyện Sơn Động, tỉnh Bắc Giang, tác giả đã lựa chọn và đề xuất các chỉ tiêu đầu vào cho mô hình phân loại thảm thực vật rừng dễ cháy theo nguy cơ cháy như sau (xem bảng 2).

b) Trọng số và thang điểm phân cấp nguy cơ cháy rừng của các chỉ tiêu:

Trọng số của các chỉ tiêu đầu vào được xác định dựa trên vai trò và tầm quan trọng

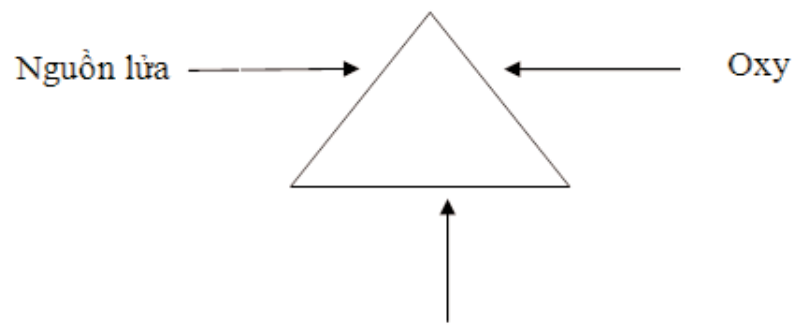

Vật liệu cháy

Hình 1: Các nhân tố gây lên cháy rừng (Phạm Ngọc Hưng, 1998) 
Bảng 1: Đề xuất phân cấp thảm thực vật rừng dễ cháy theo nguy cơ cháy

\begin{tabular}{|c|c|c|}
\hline STT & $\begin{array}{l}\text { Đề xuất phân cấp nguy co' } \\
\text { cháy rừng }\end{array}$ & $\begin{array}{l}\text { Phân cấp dụ́ báo cháy rừng theo QĐ } \\
\text { 127/2000/QĐ-BNN-KL của Bộ NN\&PTNT }\end{array}$ \\
\hline 1 & Cấp I: Nguy cơ cháy thấp & Cấp I: Nguy cơ cháy thấp \\
\hline 2 & Cấp II: Nguy cơ cháy trung bình & Cấp II: Nguy cơ cháy trung bình \\
\hline 3 & Cấp III: Nguy cơ cháy cao & Cấp III: Nguy cơ cháy cao \\
\hline & \multirow{2}{*}{ Cấp IV: Nguy cơ cháy rất cao } & Cấp IV: Nguy hiểm \\
\hline & & Cấp V: Cực kỳ nguy hiểm \\
\hline
\end{tabular}

Bảng 2: Đề xuất các chỉ tiêu cho phân loại thảm thực vật rừng theo nguy cơ cháy

\begin{tabular}{|c|c|c|}
\hline Các nhân tố & Chỉ tiêu lụ̣a chọn & Nguồn dữ liệu đầu vào \\
\hline \multirow{6}{*}{$\begin{array}{c}\text { Điều } \\
\text { kiện } \\
\text { tự } \\
\text { nhiên }\end{array}$} & 1) Kiểu thảm thực vật rừng & Bản đồ phân loại thảm thực vật rừng \\
\hline & $\begin{array}{l}\text { 2) Nhiệt độ trung bình ngày các tháng mùa khô } \\
\text { (từ tháng } 11 \text { đến tháng } 4 \text { năm sau) }\end{array}$ & $\begin{array}{l}\text { Số liệu quan trắc của các Trạm Khí } \\
\text { tượng Thủy văn }\end{array}$ \\
\hline & $\begin{array}{l}\text { 3) Lượng mưa trung bình tháng (tháng } 11 \text { đến } \\
\text { tháng } 4 \text { năm sau) }\end{array}$ & $\begin{array}{l}\text { Số liệu quan trắc của các Trạm Khí } \\
\text { tượng Thủy văn }\end{array}$ \\
\hline & $\begin{array}{l}\text { 4) Tốc độ gió trung bình ngày (từ tháng } 11 \text { đến } \\
\text { tháng } 4 \text { năm sau) }\end{array}$ & $\begin{array}{l}\text { Số liệu quan trắc của các Trạm Khí } \\
\text { tượng Thủy văn }\end{array}$ \\
\hline & 5) Độ dốc của địa hình & Mô hình số độ cao \\
\hline & 6) Hướng sườn đón gió & Mô hình số độ cao \\
\hline \multirow{2}{*}{$\begin{array}{l}\text { Điều kiện } \\
\text { kinh tế } \\
\text { xã hội }\end{array}$} & $\begin{array}{l}\text { 7) Khoảng cách từ các khu dân cư đến các } \\
\text { khu rừng }\end{array}$ & Nội suy từ bản đồ hiện trạng sử dụng đất \\
\hline & $\begin{array}{l}\text { 8) Khoảng cách từ đất canh tác nương rẫy đến } \\
\text { các khu rừng }\end{array}$ & Nội suy từ bản đồ hiện trạng sử dụng đất \\
\hline
\end{tabular}

ảnh hưởng đến cháy rừng, với tổng điểm trọng số của 8 chỉ tiêu luôn bằng 1 và được xác định giá trị tương ứng từ 0,05-0,4 (xem bảng 3).

\subsection{Xây dựng mô hình phục vụ phân} loại thảm thực vật rừng theo nguy co' cháy

Trên cơ sở bản đồ của 8 chỉ tiêu đầu vào ở dạng dữ liệu Raster, sử dụng công cụ ModelBuilder trong phần mềm ArcGIS để xây dựng mô hình tính toán phân cấp nguy cơ cháy rừng. Mô hình với 8 chỉ tiêu đầu vào này rất đơn giản và linh hoạt trong quá trình sử dụng. Bất kỳ nhưng thay đổi hay hiệu chỉnh một trong 8 chỉ tiêu đầu vào sẽ không làm ảnh hưởng đến mô hình và thao tác chạy lại mô hình chỉ thông qua động tác nhấp chuột có thể cho ra kết quả đầu ra (xem hình 2).

\subsection{Thuâat toán tính toán và phân cấp nguy cơ cháy rừng của mô hình}

- Bài toán trung bình cộng có trọng số: Thang điểm của từng lớp thông tin đầu vào (ở dạng Raster) từ 1 đến 4 điểm tương ứng với 4 cấp nguy cơ cháy rừng (rất thấp: 1 điểm; thấp: 2 điểm; cao: 3 điểm và rất cao: 4 điểm). Bài toán trung bình cộng có trọng số được sử dụng để tính nguy cơ cháy rừng, thực hiện bằng cộng cụ Weighted Overlay trong phần mềm ArcGIS. Đây là công cụ xử lý dữ liệu GIS rất mạnh, cho phép tính toán nhanh. Thuật toán có công thức như sau: 
Bảng 3: Trọng số và điểm cho phân cấp nguy cơ cháy rừng theo các chỉ tiêu đầu vào được lựa chọn

\begin{tabular}{|c|c|c|c|c|c|c|}
\hline STT & $\begin{array}{l}\text { Chỉ tiêu } \\
\text { đầu vào }\end{array}$ & \begin{tabular}{|c|} 
Trọng \\
số
\end{tabular} & Khoảng giá trị & Điểm & \begin{tabular}{|l} 
Phân cấp \\
rủi ro
\end{tabular} & $\begin{array}{l}\text { Nguy co' } \\
\text { cháy }\end{array}$ \\
\hline & \multirow{4}{*}{$\begin{array}{c}\text { Kiểu } \\
\text { thảm } \\
\text { thực } \\
\text { vật } \\
\text { rừng }\end{array}$} & \multirow{4}{*}{0,4} & $\begin{array}{l}\text { Rừng gỗ trồng núi đất, Đất đã trồng trên núi } \\
\text { đất (Thông, Keo, Bạch đàn) }\end{array}$ & 4,00 & Cấp 4 & Rất cao \\
\hline & & & $\begin{array}{l}\text { Rừng tre nứa, rừng hỗn giao lá rộng và tre } \\
\text { nứa, đất có cây gố tái sinh núi đất }\end{array}$ & 3,00 & Cấp 3 & Cao \\
\hline & & & $\begin{array}{l}\text { Rừng hỗn giao cây lá rộng và nửa rụng lá, } \\
\text { rừng lá rộng thường xanh tái sinh }\end{array}$ & 2,00 & Cấp 2 & Trung bình \\
\hline & & & Rừng lá rộng thường xanh trung bình và giàu & 1,00 & Cấp 1 & Thấp \\
\hline & \multirow{4}{*}{$\begin{array}{l}\text { Nhiệt } \\
\text { độ } \\
\text { trung } \\
\text { bình } \\
\text { ngày }\end{array}$} & \multirow{4}{*}{0,15} & $>25^{\circ}$ & 4,00 & Cấp 4 & Rất cao \\
\hline & & & $22^{0}-25^{0}$ & 3,00 & Cấp 3 & Cao \\
\hline & & & $20^{\circ}-22^{\circ}$ & 2,00 & Cấp 2 & Trung bình \\
\hline & & & $<20^{\circ}$ & 1,00 & Cấp 1 & Thấp \\
\hline & \multirow{4}{*}{$\begin{array}{c}\text { Lượng } \\
\text { mưa } \\
\text { trung } \\
\text { bình } \\
\text { tháng }\end{array}$} & \multirow{4}{*}{0,15} & $<120 \mathrm{~mm}$ & 4,00 & Cấp 4 & Rất cao \\
\hline & & & $120-130 \mathrm{~mm}$ & 3,00 & Cấp 3 & Cao \\
\hline & & & $130-140 \mathrm{~mm}$ & 2,00 & Cấp 2 & Trung bình \\
\hline & & & $>140 \mathrm{~mm}$ & 1,00 & Cấp 1 & Thấp \\
\hline & \multirow{4}{*}{$\begin{array}{c}\text { Tốc } \\
\text { độ gió } \\
\text { trung } \\
\text { bình } \\
\text { ngày }\end{array}$} & \multirow{4}{*}{0,10} & $>7,0 \mathrm{~m} / \mathrm{s}$ & 4,00 & Cấp 4 & Rất cao \\
\hline & & & $4,3-6,9 \mathrm{~m} / \mathrm{s}$ & 3,00 & Cấp 3 & Cao \\
\hline & & & $1,4-4,2 \mathrm{~m} / \mathrm{s}$ & 2,00 & Cấp 2 & Trung bình \\
\hline & & & $<1,4 \mathrm{~m} / \mathrm{s}$ & 1,00 & Cấp 1 & Thấp \\
\hline & \multirow{4}{*}{$\begin{array}{c}\text { Độ } \\
\text { dốc } \\
\text { địa } \\
\text { hình }\end{array}$} & \multirow{4}{*}{0,05} & $>35^{0}$ & 4,00 & Cấp 4 & Rất cao \\
\hline & & & $25^{0}-35^{0}$ & 3,00 & Cấp 3 & Cao \\
\hline & & & $15^{0}-25^{0}$ & 2,00 & Cấp 2 & Trung bình \\
\hline & & & $<15^{0}$ & 1,00 & Cấp 1 & Thấp \\
\hline & \multirow{7}{*}{$\begin{array}{l}\text { Hướng } \\
\text { sườn } \\
\text { đón } \\
\text { gió }\end{array}$} & \multirow{7}{*}{0,05} & $\operatorname{TN}\left(180^{\circ}-270^{\circ}\right)$ & 4,00 & Cấp 4 & Rất cao \\
\hline & & & TB $\left(270^{\circ}-315^{\circ}\right)$ & \multirow{2}{*}{3,00} & \multirow{2}{*}{ Cấp 3} & \multirow{2}{*}{ Cao } \\
\hline & & & ĐB $\left(45^{\circ}-90^{\circ}\right)$ & & & \\
\hline & & & TB $\left(315^{\circ}-360^{\circ}\right)$ & \multirow{2}{*}{2,00} & \multirow{2}{*}{ Cấp 2} & \multirow{2}{*}{ Trung bình } \\
\hline & & & ĐB $\left(0^{\circ}-45^{\circ}\right)$ & & & \\
\hline & & & ĐN $\left(135^{\circ}-180^{\circ}\right)$ & \multirow{2}{*}{1,00} & \multirow{2}{*}{ Cấp 1} & \multirow{2}{*}{ Thấp } \\
\hline & & & $0 Ð\left(90^{\circ}-135^{\circ}\right)$ & & & \\
\hline & \multirow{4}{*}{$\begin{array}{l}\text { Hướng } \\
\text { sườn } \\
\text { đón } \\
\text { gió }\end{array}$} & \multirow{4}{*}{0,05} & 0 & 4,00 & Cấp 4 & Rất cao \\
\hline & & & 0 & 3,00 & Cấp 3 & Cao \\
\hline & & & 0 & 2,00 & Cấp 2 & Trung bình \\
\hline & & & 0 & 1,00 & Cấp 1 & Thấp \\
\hline & \multirow{4}{*}{$\begin{array}{c}\text { Khoảng } \\
\text { cách từ } \\
\text { đất canh } \\
\text { tác } \\
\text { nương } \\
\text { rẫy đến } \\
\text { rừng }\end{array}$} & \multirow{4}{*}{0,05} & 0 & 4,00 & Cấp 4 & Rất cao \\
\hline & & & 0 & 3,00 & Cấp 3 & Cao \\
\hline & & & 0 & 2,00 & Cấp 2 & Trung bình \\
\hline & & & 0 & 1,00 & Cấp 1 & Thấp \\
\hline
\end{tabular}


$\mathrm{R}=\operatorname{ROUND}\left\{\left(\mathrm{k}_{1}{ }^{*} \mathrm{l}_{1}+\mathrm{k}_{2}{ }^{*} \mathrm{I}_{2}+\mathrm{k}_{3}{ }^{*} \mathrm{I}_{3}+\ldots+\right.\right.$ $\left.\left.\mathrm{k}_{\mathrm{n}}{ }^{*} \mathrm{I}\right)\right\}$

Trong đó: $\mathrm{R}$ là cấp nguy cơ cháy rừng; $\mathrm{k}_{1}, \mathrm{k}_{2}, \mathrm{k}_{3}$ và $\mathrm{kn}$ là trọng số tương ứng của các lớp thông tin đầu vào $I_{1}, I_{2}, I_{3}$ và $I_{n}$. Tổng $k_{1}+k_{2}+k_{3}+\ldots .+k_{n}=1$.

Trong hình hình 3 (xem hình 3), bản đồ đầu vào InRas1 có trọng số là 0,75 ; InRas2 có trọng số 0,25 và giá trị các pixel từ 1 đến 4 của các lớp thông tin đầu vào tương ứng với 4 cấp nguy cơ cháy rừng. Cách tính giá trị pixel thứ nhất của bản đồ đầu ra OutRas như sau: $0,75 * 2+0,25 * 3=2,25$. Vì giá trị của các pixel đầu ra là số nguyên dương nên kết quả được làm tròn là 2.

Quy trình kỹ thuật thành lập bản đồ nguy cơ cháy rừng huyện Sơn Động tỉnh Bắc Giang gồm các bước sau (xem hình 4):

\section{Kết quả nghiên cứu}

\subsection{Khu vực nghiên cứu}

Sơn Động là một huyện nằm ở cuối tỉnh Bắc Giang, phía đông giáp huyện Đình Lập của tỉnh Lạng Sơn và huyện $B a$ Chẽ của tỉnh Quảng Ninh, phía nam giáp huyện Hoành Bồ, thành phố Uông Bí và thị xã Đông Triều của tỉnh Quảng Ninh, phía tây giáp hai huyện Lục Ngạn và Lục Nam cùng thuộc tỉnh Bắc Giang. Đây là một trong những huyện có diện tích rừng tự nhiên lớn với hơn 80 nghìn héc-ta. Với lợi thế về diện tích rừng và đất lâm nghiệp chiếm 71,92\% diện tích tự nhiên của huyện, rừng Sơn Động có vai trò quan trọng trong phòng hộ đầu nguồn, bảo vệ môi trường, làm đẹp cảnh quan, góp phần điều tiết khí hậu, hạn chế thiên tai, thúc đẩy phát triển kinh tế - xã hội của địa phương và các vùng phụ cận. (xem hình 5)

\subsection{Dữ liệu đầu vào}

Nhóm nghiên cứu sử dụng ảnh Landsat 8 OLI và Sentinel 2 (xem hình 6) được chụp tháng 8 năm 2017 và dữ liệu kiểm kê rừng nhận được từ Chi cục kiểm lâm Bắc Giang là nguồn dữ liệu đầu vào để tính toán 8 tham số.

\subsection{Kết quả thực nghiệm}

\subsubsection{Các sản phẩm trung gian}

Nhóm nghiên cứu tiến hành thành lập 8 nhóm liệu đầu vào thành phần để thực hiện tính toán bản đồ nguy cơ cháy rừng với các giá trị thuộc tính được phân cấp mô tả trên phần 2.3 (xem hình 7).

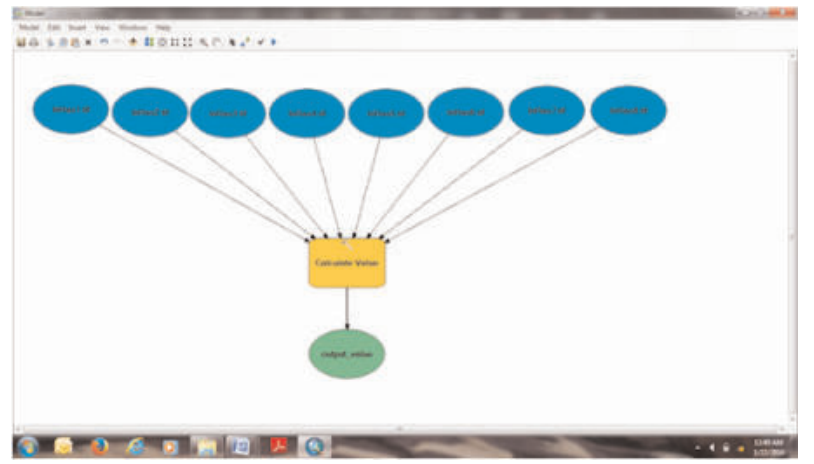

Hình 2: Mô hình phân cấp nguy cơ cháy rừng xây dụng trong ArcGIS với 8 chỉ tiêu đầu vào

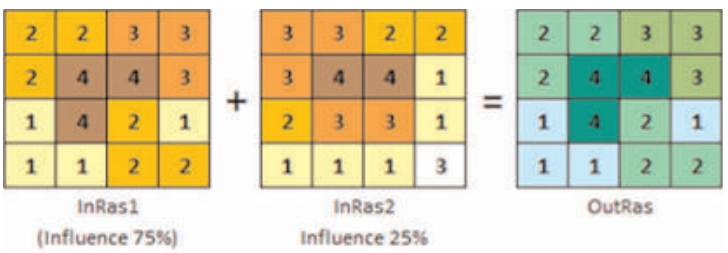

Hình 3: Sơ đồ minh họa bài toán trung bình cộng có trọng số bằng công cu Weighted Overlay trong phần mềm ArcGIS 
3.3.2. Thành lập bản đồ nguy cơ cháy rừng

Sản phẩm bản đồ nguy cơ cháy rừng huyện Sơn Động tỉnh Bắc Giang được mô tả trên hình (xem hình 8).

\section{4. Đánh giá độ chính xác của kết quả nghiên cứu}

Căn cứ trên bản đồ nguy cơ cháy rừng huyện Sơn Động tỉnh Bắc Giang được thành lập, nhóm nghiên cứu đã nhận được sự giúp đỡ của các cán bộ Ban quản lý rừng Tây Yên Tử, Chi cục Kiểm lâm Bắc Giang trong công tác thực địa, đánh giá độ chính xác của bản đồ nguy cơ cháy rừng. Tiêu chí lựa chọn các điểm đánh giá độ chính xác được xác định như sau:

- Nằm trên trục đường giao thông chính;

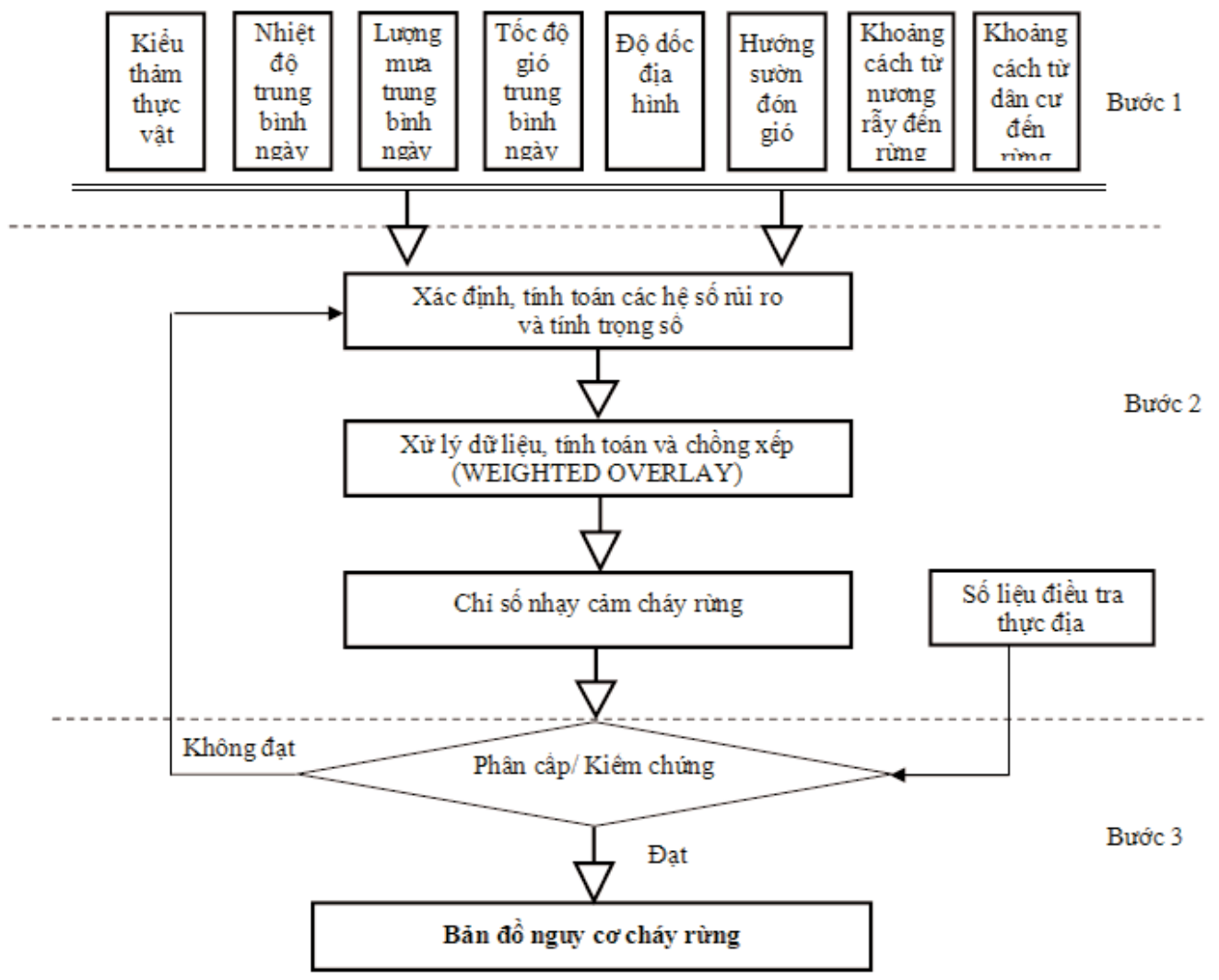

Hình 4: Quy trình kỹ thuật thành lập bản đồ nguy cơ cháy rừng 


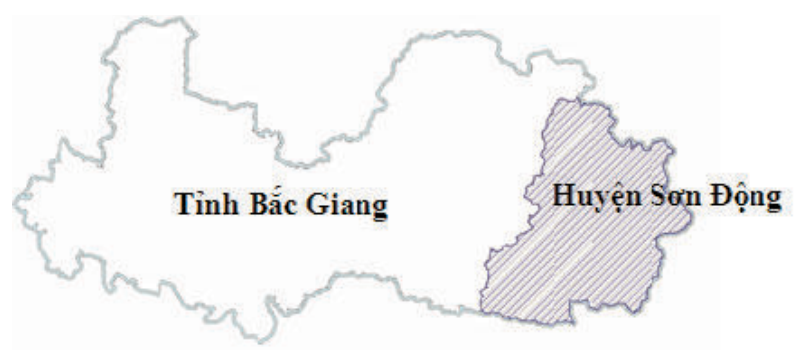

Hình 5: Vị trí huyện Sơn Động tỉnh Bắc Giang

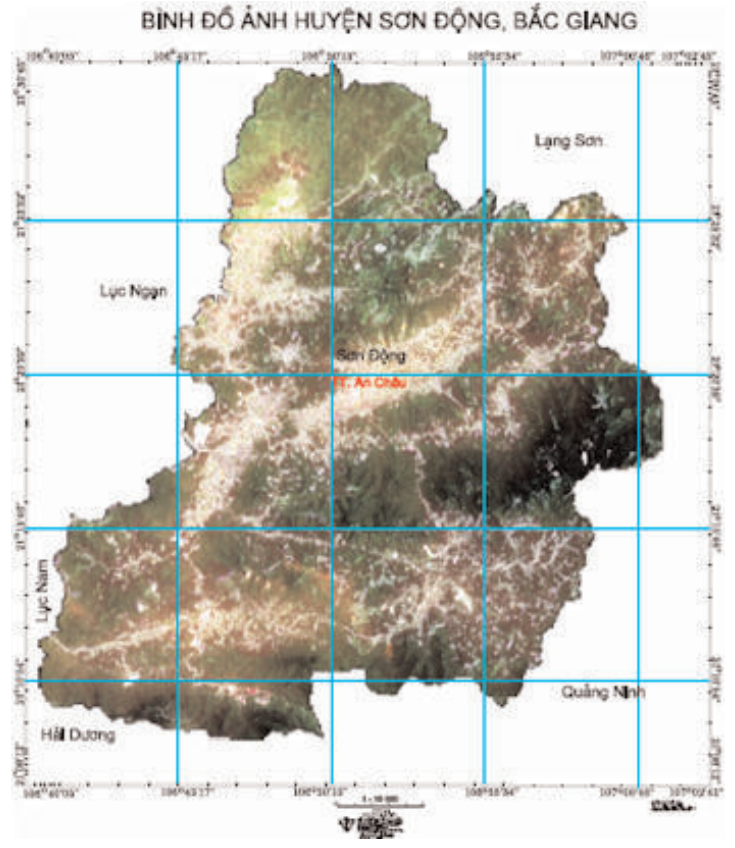

Hình 6: Bình đồ ảnh 1:50.000 huyện Sơn Động tỉnh Bắc Giang được thành lập tư ảnh Sentinel 2
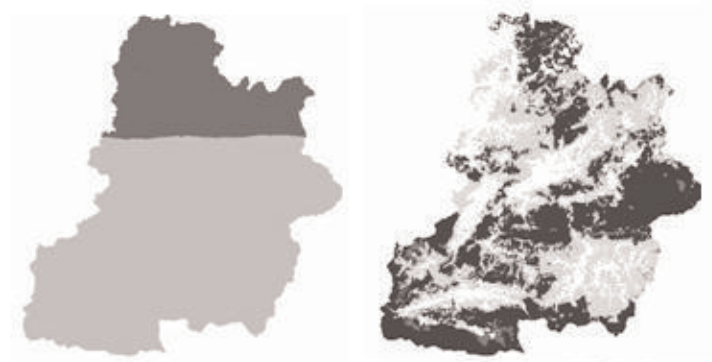

Nhiệt độ
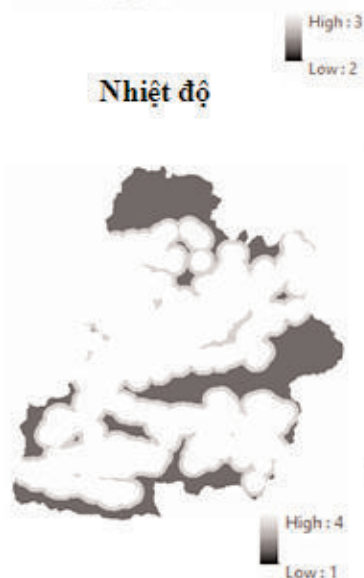

Khoảng cách đến khu dân cư

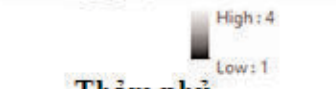

Thảm phủ

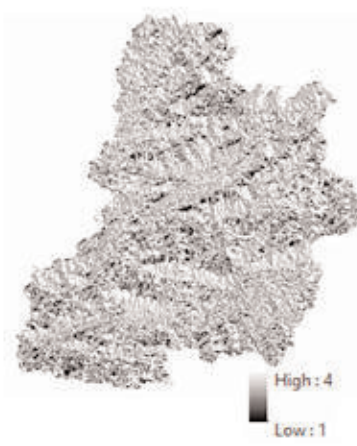

Hướng sườn
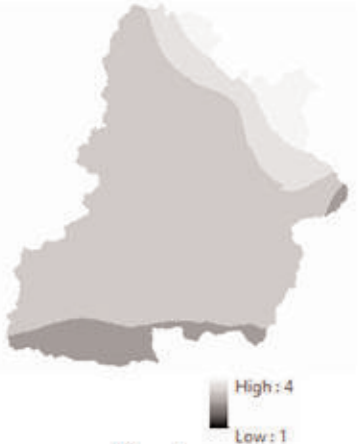

Lượng mưa

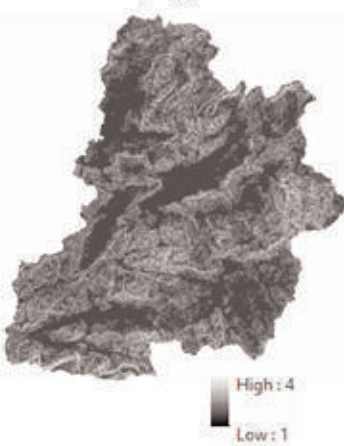

Độ dốc

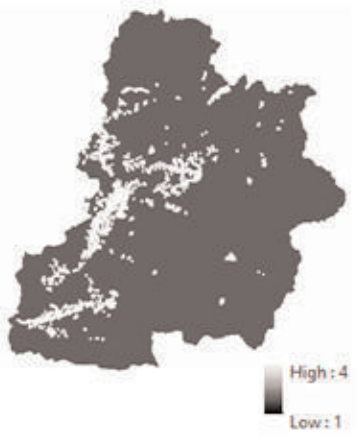

Khoảng cách đến nương rẫy

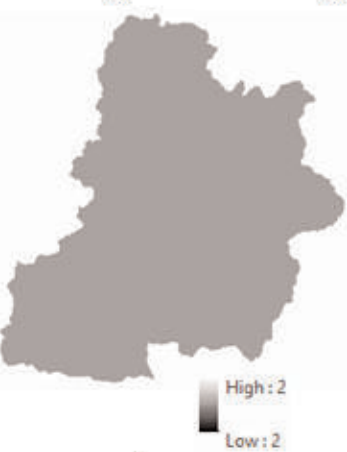

Tốc độ gió

Hình 7: Nhóm 8 dữ liệu đầu vào thành phần 
phục, chỉnh sửa trong quá trình thực hiện nghiên cứu tiếp theo để nâng cao độ chính xác kết quả nghiên cứu.

\section{Kết luận}

Có thể nhận thấy trên bản đồ nguy cơ cháy rừng huyện Sơn Động, tỉnh Bắc Giang, rừng tự nhiên hiện nay phân bố chủ yếu ở khu vực phía Đông và Tây Nam của huyện, với cấu trúc rừng thuộc cấu trúc kiểu rừng thưa cây lá rộng hơi khô nhiệt đới, chủ yếu là loại rừng hỗn giao tre nứa, phân bố tại những khu vực có vĩ độ cao, xa khu vực dân cư sinh sống nên phần lớn diện tích được tính toán phân cấp khu vực có nguy cơ cháy thấp. Tiếp đến là rừng trồng, thành phần loài rất đa dạng bao gồm các loài sau: Bạch đàn (4900 ha), Keo (65000 ha), Vải (7000 ha), còn lại là rừng hỗn giao (Keo + Bạch đàn + Muông + Trầm + Lát). Ở loại

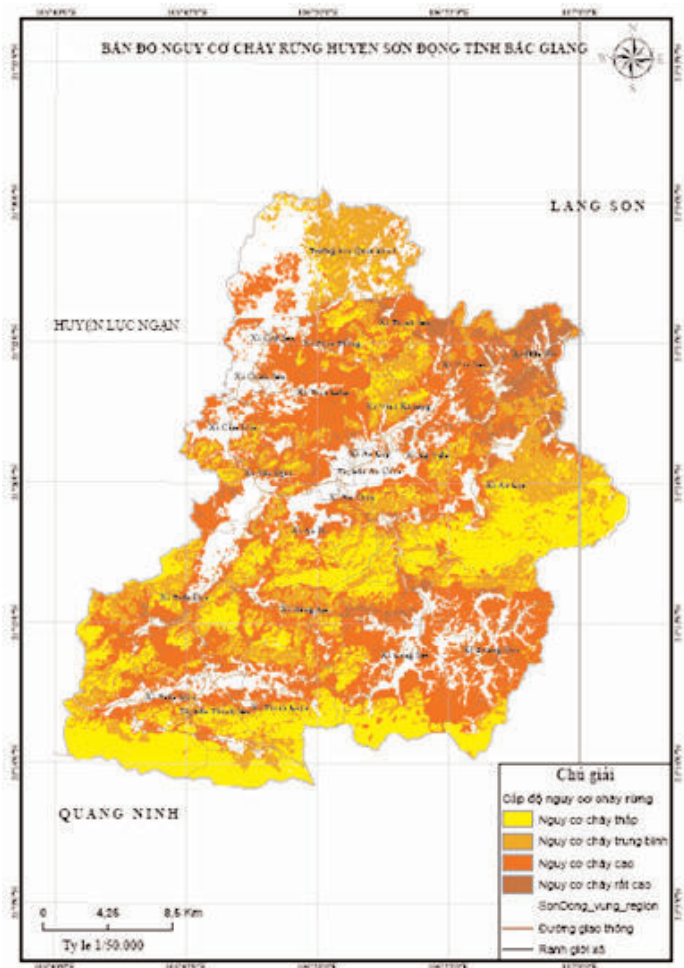

Hình 8: Bản đồ nguy cơ cháy rừng huyện Sơn Động, tỉnh Bắc Giang hình này, độ cao phân bố từ 50 - 1050m, phần lớn cây trồng là các cây keo và bạch đàn là loại cây dễ bắt lửa do có chứa tinh dầu nên khi lá rụng xuống sẽ tạo nên nguồn vật liệu cháy rất nguy hiểm. Bên cạnh đó, do kỹ thuật trồng trọt của người dân đốt gốc cây sau khi thu hoạch của người dân, nên nguy cơ bắt cháy tại những khu vực rừng trồng được phân cấp từ cao đến rất cao.

Việc ứng dụng kết hợp công nghệ viễn thám và GIS đã phát huy được những thế mạnh riêng của từng hình công nghệ. Kết quả nghiên cứu đã thành lập thành công bản đồ nguy cư cháy rừng huyện Sơn Động tỉnh Bắc Giang trên cơ sở sử dụng cách tiếp cận vật liệu cháy trong các kiểu rừng để phục vụ công tác phòng chống cháy rừng tại tỉnh Bắc Giang. Kết quả nghiên cứu sẽ cung cấp một giải pháp phòng chống cháy rừng

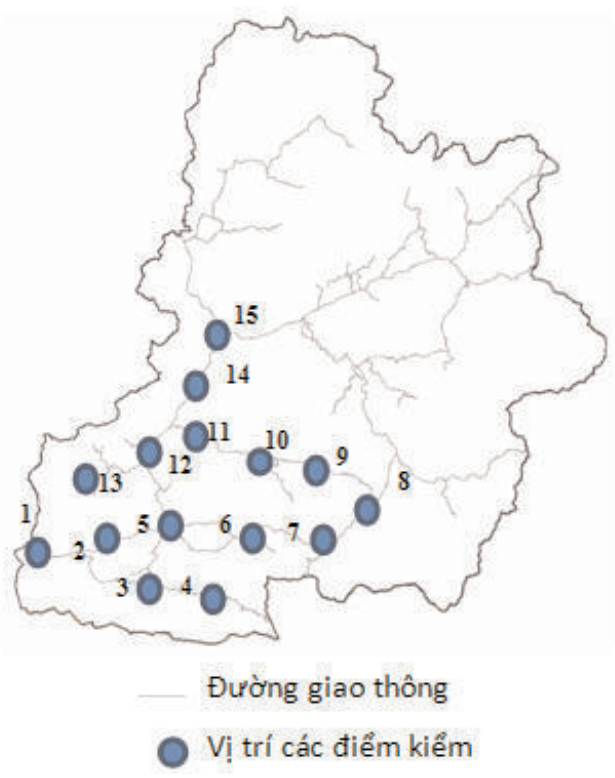

Hình 9: Vị trí các điểm kiểm tra độ chính xác 
hiệu quả phục vụ công tác quản lý rừng tại địa phương. $\mathrm{O}$

\section{Tài liệu tham khảo}

[1]. Lê Đức Anh, Nguyễn Văn Chiến, 1985. Địa hình và địa mạo Tây Nguyên Tây Nguyên các điều kiện tự nhiên và tài nguyên thiên nhiên. Nhà Xuất bản Khoa học và Kỹ thuật, Hà Nội.

[2]. Phạm Ngọc Hưng (1998). Xây dựng phương pháp dự báo khả năng xuất hiện nguy cơ cháy rừng thông nưa ở Quảng Ninh. Viện Khoa học Lâm nghiệp.

[3]. Bộ Nông nghiệp và phát triển nông thôn, 2004. Cẩm nang ngành lâm nghiệp, Chương "Phòng cháy và chữa cháy rừng". Chương trình hỗ trợ ngành lâm nghiệp và đối tác.

[4]. Bế Minh Châu, 2001. Nghiên cứu ảnh hưởng của điều kiện khí tượng đến độ ẩm và khả năng cháy của vật liệu dưới rừng thông góp phần hoàn thiện phương pháp dự báo cháy rừng tại một số vùng trọng điểm thông miền Bắc Việt Nam. Luận án Tiến sĩ Nông nghiệp, Trường Đại học Lâm nghiệp.

[5]. Nguyễn Đình Dương, 2006. Phân loại lớp phủ Việt Nam bằng tư liệu MODIS đa thời gain và thuật toán phân tích đồ thị đường cong phổ phản xạ. Tuyển tập các công trình khoa học, Hội nghị khoa học Địa lý - Địa chính, Hà Nội.

[6]. Phạm Ngọc Hưng, 2004. Quản lý cháy rừng ở Việt Nam. Nhà Xuất bản Nghệ An.

[7]. Gromovist R., Juvelius M., Heikkila T., 1993. Handbook on forest fire. Helinki:76 $-240$.

[8]. Keith S., Brown, 1979. Ecological Geography and Evolution in Neotropical Forests. University of Campinas, Brazil.

[9]. Yichun Xie, Zongyao Sha and Mei Yu, 2008. Remote sensing imagery in vegetation mapping: a review. Journal of Plant Ecology1 (1): 9-23.0

\section{Summary}

\section{Application of remote sensing and GIS for investigating the contributions of com- bustible forest materials in forest fire prevention in Bac Giang province}

Pham Minh Hai, Institute of Geodesy and Cartography

\section{Vu Ngoc Phan, Hanoi University of Natural Resources and Environment}

Forest fire has caused great negative consequences on the environment, natural resources and human. Climate change with prolonged droughts has made forest fires become increasingly serious. The research on forest fire prevention and control in Vietnam shows some limitations as follows: using mainly ground meteorological data; the use of remote sensing images in forest fire forecasts is only for provincial level. There has been no studies go into the reasearch of combustible material as well as their fire ratings on forest fire phenomena. Therefore, the development of combustible material research for forest fire risk prediction plays a crucial role in forest fire prevention and fighting by the local specialized agencies. The experimental site of the study is Son Dong district, Bac Giang province with two main types of forest research: plantation and natural forest. $O$ 